\title{
ON WEIGHTED HARDY-TYPE INEQUALITIES
}

\author{
Chian Yeong Chuah, Fritz Gesztesy, Lance L. Littlejohn, Tao Mei, \\ ISAAC MiCHAEL AND MiChAEL M. H. PANG
}

Abstract. We revisit weighted Hardy-type inequalities employing an elementary ad hoc approach that yields explicit constants. We also discuss the infinite sequence of power weighted Birman-Hardy-Rellich-type inequalities and derive an operator-valued version thereof.

Mathematics subject classification (2010): 26D10, 34A40, 35A23.

Keywords and phrases: Weighted Hardy inequalities, Birman's inequalities, operator-valued inequalities.

\section{REFERENCES}

[1] W. Arendt, C. K. Batty, M. Hieber, And F. Neubrander, Vector-Valued Laplace Transforms and Cauchy Problems, Monographs in Mathematics, Vol. 96, Birkhäuser, Basel, 2001.

[2] A. A. BALins Ky, W. D. Evans, AND R. T. Lewis, The Analysis and Geometry of Hardy's Inequality, Universitext, Springer, 2015.

[3] H. Baumgärtel And M. Wollenberg, Mathematical Scattering Theory, Operator Theory: Advances and Applications, Vol. 9, Birkhäuser, Boston, 1983.

[4] M. S. BiRman, The spectrum of singular boundary problems, Mat. Sb., 55, 97, 1961, 125-174 (Russian). Engl. transl. in Amer. Math. Soc. Transl., Ser. 2, 53 (1966), 23-80.

[5] M. S. Birman And M. Z. Solomjak, Spectral Theory of Self-Adjoint Operators in Hilbert Space, Reidel, Dordrecht, 1987.

[6] J. S. BRAdLEy, Hardy inequalities with mixed norms, Canad. Math. Bull., 21, 4, 1978, 405-408.

[7] P. Cembranos and J. Mendoza, Banach Spaces of Vector-Valued Functions, Lecture Notes in Mathematics, Vol. 1676, Springer, Berlin, 1997.

[8] R. S. Chisholm AND W. N. Everitt, On bounded integral operators in the space of integrablesquare functions, Proc. Roy. Soc. Edinburgh (A), 69, 3, 1970/71, 199-204.

[9] R. S. Chisholm, W. N. Everitt, AND L. L. LitTlejohn, An integral operator inequality with applications, J. of Inequal. Appls, 3, 3, 1999, 245-266.

[10] E. B. Davies, Spectral Theory and Differential Operators, Cambridge Studies in Advanced Mathematics, Vol. 42, Cambridge University Press, Cambridge, UK, 1995.

[11] J. Diestel And J. J. Uhl, Vector Measures, Mathematical Surveys, Vol. 15, Amer. Math. Soc., Providence, RI, 1977.

[12] D. E. Edmunds AND W. D. Evans, Hardy Operators, Function Spaces, and Embeddings, Springer, Berlin, 2004.

[13] F. Gesztesy, L. Littlejohn, I. Michael, and R. Wellman, On Birman's Sequence of HardyRellich-Type Inequalities, J. Diff. Eq., 264, 4, 2018, 2761-2801.

[14] I. M. GLAZman, Direct Methods of Qualitative Spectral Analysis of Singular Differential Operators, Israel Program for Scientific Translations, Jerusalem, 1965, Daniel Davey \& Co., Inc., New York, 1966.

[15] A. Gogatishvili, A. Kufner, L.-E. Persson, And A. Wedestig, An equivalence theorem for integral conditions related to Hardy's inequality, Real Anal. Exchange, 29, 2, 2003/04, 867-880.

[16] F. Hansen, Non-commutative Hardy inequalities, Bull. Lond. Math. Soc., 41, 6, 2009, 1009-1016.

[17] F. Hansen, K. Krulić, J. PeČarić, And L.-E. Persson, Generalized noncommutative Hardy and Hardy-Hilbert type inequalities, Intl. J. Math., 21, 10, 2010, 1283-1295. 
[18] G. H. HARDY, Notes on some points in the integral calculus, XLI. On the convergence of certain integrals and series, Messenger Math., 45, 1, 1915, 163-166.

[19] G. H. HARDY, Notes on some points in the integral calculus, LI. On Hilbert's double-series theorem, and some connected theorems concerning the convergence of infinite series and integrals, Messenger Math., 48, 1, 1919, 107-112.

[20] G. H. HARDY, Note on a theorem of Hilbert, Math. Z., 6, 3-4, 1920, 314-317.

[21] G. H. HARDY, Notes on some points in the integral calculus, LX. An inequality between integrals, Messenger Math., 54, 1, 1925, 150-156.

[22] G. H. HARDY, Notes on some points in the integral calculus LXIV, Messenger Math., 57, 1, 1928, $12-16$.

[23] G. H. Hardy, J. E. Littlewood, And G. Pólya, Inequalities, Cambridge University Press, Cambridge, UK, reprinted, 1988.

[24] E. Hille AND R. S. Phillips, Functional Analysis and Semi-Groups, Colloquium Publications, Vol. 31, rev. ed., Amer. Math. Soc., Providence, RI, 1985.

[25] M. KiAn, On a Hardy operator inequality, Positivity, 22, 3, 2018, 773-781.

[26] A. Kufner, L. Maligranda And L.-E. Persson, The Hardy Inequality: About its History and Some Related Results, Vydavatelský Servis, Pilsen, 2007.

[27] A. Kufner, L.-E. Persson, AND N. SAmKo, Weighted Inequalities of Hardy Type, 2nd ed., World Scientific, Singapore, 2017.

[28] S. T. KURODA, An Introduction to Scattering Theory, Aarhus University Lecture Notes Series, No. 51, 1978.

[29] J. MikusińSKI, The Bochner Integral, Academic Press, New York, 1978.

[30] B. MucKenhoupt, Hardy's inequality with weights, Studia Math., 44, 1, 1972, 31-38.

[31] M. NASs Yrova, Weighted Inequalities Involving Hardy-type and Limiting Geometric Mean Operators, doctoral dissertation, Dept. of Math., Luleå University of Technology, March 2002.

[32] M. NASYRova AND V. STEPANOv, On weighted Hardy inequalities on semiaxis for functions vanishing at the endpoints, J. Inequal. Appl., 1, 3, 1997, 223-238.

[33] M. NASYROVA AND V. STEPANOV, On maximal overdetermined Hardy's inequality of second order on a finite interval, Math. Bohem., 124, 2-3, 1999, 293-302.

[34] B. Opic And A. Kufner, Hardy-Type Inequalities, Pitman Research Notes in Mathematics Series, Vol. 219. Longman Scientific \& Technical, Harlow, 1990.

[35] B. J. PetTis, On integration in vector spaces, Trans. Am. Math. Soc., 44, 2, 1938, 277-304.

[36] G. Talenti, Osservazioni sopra una classe di disuguaglianze, Rend. Sem. Mat. Fis. Milano, 39, 1, 1969, 171-185.

[37] G. TOMASELLI, A class of inequalities, Boll. Un. Mat. Ital., 2, 4, 1969, 622-631.

[38] K. YosidA, Functional Analysis, 6th ed., Springer, Berlin, 1980. 